\title{
The Causes of Non-Compliance to Treatment Among Type 2 Diabetes Mellitus Patients
}

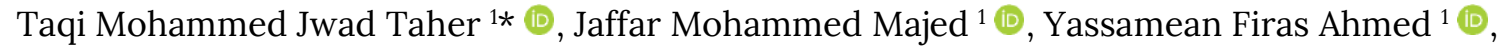 \\ Firas Turki Rashed Sarray ${ }^{2}$ (c)
}

${ }^{1}$ College of Medicine, Wasit University, IRAQ

${ }^{2} \mathrm{Al}$-Zahraa Teaching Hospital, Wasit Health Directorate, IRAQ

*Corresponding Author: ttahir@uowasit.edu.iq

Citation: Taher TMJ, Majed JM, Ahmed YF, Sarray FTR. The Causes of Non-Compliance to Treatment Among Type 2 Diabetes Mellitus Patients. Journal of Contemporary Studies in Epidemiology and Public Health. 2021;2(2):ep21006. https://doi.org/10.30935/jconseph/11276

\begin{abstract}
Background: Generally, type 2 diabetes mellitus can end with many complications, which leads to severe unwanted health problems that can be prevented by strict adherence to the prescribed methods of management conducted by the physician. So, this study was designed to evaluate the range of the patient's compliance to therapy (drug, diet, and exercise).

Methods: An analytic cross-sectional study evaluated 380 convenient samples with type 2 diabetes visiting private internal medicine clinics in AL-Kut city and over 18 years. All patients were consented to participate and full a pretested questionnaire consisting of questions related to the causes of non-compliance to the management protocol. Results: The sample consisted of 209(55\%) females, $91.8 \%$ were from urban regions, and $43.2 \%$ had a college degree or above educational level. There were $64.2 \%$ who was continuously measuring their glucose level, but only $39.2 \%$ visiting the doctors regularly. On the other hand, most patients (78.4\%) declared that they complied with drug therapy. On the other hand, only $20.5 \%$ of patients always follow the doctor's instructions regarding a healthy diet, while $9.7 \%$ mentioned compliance with regular exercise. The significant causes of non-compliance to the drug were costly drugs in (25.4\%) and (19.8\%) for the forgetting. There were 123(62.4\%) who did not care about healthy food, and $119(42 \%)$ could not practice exercise because they could not do that.
\end{abstract}

Conclusion: The higher rate of non-compliance for diet and exercise focuses on the need for an actual intervention to increase the awareness about the importance of these two management types.

Keywords: diabetes mellitus, adherence, compliance, anti-diabetic drugs, healthy diet

Received: 2 Jul. 2021 Accepted: 6 Sep. 2021

\section{INTRODUCTION}

The disease Diabetes mellitus (DM) is one of the metabolic disorders distinguished by high blood sugar rises from either defect in secretion of insulin (type1), insulin activity (type2), or mixed [1]. Even though type 2 diabetes usually occurs in individuals above 40 years old, it is becoming progressively common in children, teenagers, and youthful grown-ups due to diminished physical movement and unhealthy eating foods driving obesity [2]. The predominance of diabetes mellitus is developing quickly around the world and is becoming to be an epidemic. It is evaluated that there are now 285 million individuals with diabetes worldwide and expected to reach 438 million by 2030 [3]. Epidemiological information shows that all countries, wealthy and destitute, are enduring the effect of the diabetes epidemic. The effect is worse in those nations that are socially and financially impeded. In Africans, $80 \%$ of diabetes patients are undiscovered. Most of them may be asymptomatic or have gentle indications which they disregard or quality to other myths. A few may not display in a clinic out of destitution when symptomatic because of poverty [4]. DM could be a challenging disease to be treated effectively. It requires regular physician visits, self-monitoring of blood glucose, dietary alterations, works out, and organization of medicines as per plan. So, regimen adherence issues are common in people with diabetes, hence making glycemic control troublesome to achieve [5-7]. Later information from the American Diabetes Association (ADA) targets HbA1c levels less than $6 \%$ is broadly utilized as the standard biomarker for the ampleness of glycemic control $[8,9]$.

In order to manage patients with diabetes mellitus, there are two approaches, including pharmacological drugs and other nonpharmacological methods. The nonpharmacological procedures incorporate changing lifestyle, dietary alteration, and physical activity. The pharmacological approach is utilized when the nonpharmacological approach cannot attain the required result [10]. Many factors contribute to successful management programs like age, 
the number and complexity of medication, disease duration, and related psychosocial issues [11].

Adherence rates are ordinarily higher among patients with acute conditions than those with chronic conditions [12]. Researchers have found that adherence to medications in chronic disease can reach only $50 \%$ [13,14]. Numerous diabetic patients fail to follow their management regimen for different reasons, including forgetfulness, reduced understanding of the nature of their condition, prohibitively expensive drugs, and their old-style views of the illness. Other related distinguished factors are depression and emotional distress, arrangements that do not start on time, insignificant provider-patient relationship, the difficulty of regimen, restricted daily life activities, and fear of hypoglycemia at any time [15]. Poor compliance with medication is considered a common problem is contributing to an effective rate of complication and death among patients. Specialist physicians need to continuously search for the adherence rate among patients and focus on the leading causes of poor adherence by making the regimen simple, efficiently conducted, and appropriate to the patient's lifestyle.

The problem seen in previous research about the same topic includes lack of adherence, aggravation of complications, lack of exercise, non-adherence to a healthy diet, and other factors that led us to fill the gap and search for many answers concerning our research. Therefore, this study aimed to determine the prevalence of nonadherence and the contributing factors among type 2 diabetic patients in Wasit province, Iraq.

\section{PATIENTS AND METHODS}

\section{Study Design and Setting}

An analytic cross-sectional study was conducted among type 2 DM patients visiting private internal medicine clinics in AL-Kut city, Wasit province/ Iraq. AL-Kut is the centre of Wasit province, which is located in the middle of Iraq. According to the latest Iraqi census in 2014, it is assumed that around 422.793 people lived in this city from the total one and a half million people who lived in Wasit. There are many private clinics for diabetes management distributed in the city, reaching around 40 clinics. Data were collected during the period from December 2020 to May 2021.

\section{Sample Size and Sampling Procedure}

The sample was collected conveniently from 10 randomly selected internal medicine private clinics in AL-Kut city. The sample size was calculated based on the equation for cross-sectional studies, which is: " $\mathrm{n}=\mathrm{z}^{2}(\mathrm{p}-1) / \mathrm{d}^{2}$ " considering the prevalence of good knowledge $(45 \%)$ [16], the confidence level (95\%), $d=0.05$, and the power (80\%), the minimal sample size required for this study was 380 patients.

\section{Inclusion Criteria}

Patients previously diagnosed with type $2 \mathrm{DM}$ and aged more than 18 years.

\section{Exclusion Criteria}

Patients with acute and painful conditions urgently want to back home.

\section{Data Collection}

Data were collected using a structured questionnaire developed by the authors and consisting of two parts; part one contained sociodemographic features like age, gender, marital status, educational status, occupation, and place of living. The second part includes data about the prescribed methods for controlling the levels of blood sugar, which were: oral medications, a healthy diet, exercising, and insulin. In addition, causes of non-compliance to each type of treatment were also included. The presence of other chronic conditions and the duration of diabetes were also documented.

Before initiating the formal test on about ten diabetic patients, the questionnaire was pre-tested to do any necessary correction and clearness. Questionnaires were self-administered and distributed to selected patients in the selected clinics and then returned after complete filling. Body Mass Index (BMI) was calculated for each student according to their weight and height and classified according to Centres for Diseases Control and Prevention (CDC) classification to underweight, normal, overweight, and obese [17].

\section{Statistical Analysis}

Statistical Package for Social Sciences (SPSS) software version 26 was used for data analysis. Categorial data were presented by frequency and percentages, while continuous data were presented by mean and standard deviation. Association between categorical variables was obtained by Chi-square test while differences between means were calculated by both independent sample t-test and One way ANOVA test. P-value equal to or less than 0.05 was considered significant.

\section{Ethical Consideration}

Ethical approval was obtained from the College of Medicine, Wasit University. All participated patients gave their informed consent to fill the questionnaire after being informed about the study's objective and keeping their data confidential.

\section{RESULTS}

The result of this study was based on the analysis of 380 completed questionnaires from patients diagnosed with type $2 \mathrm{DM}$. The mean age and standard deviation for those patients were $(49.11 \pm 16.78)$ years, and the mean BMI was $(27.56 \pm 5.22) \mathrm{kg} / \mathrm{m}^{2}$. Female patients represented more than half $(55 \%)$ of the participants, and most of the patients (66.6\%) were married. Table 1 also shows that the majority (91.8\%) living in urban places. There were 183 patients $(43.2 \%)$ having their college degree even that $(39.2 \%)$ were unemployed or students. Only $2.6 \%$ of the sample were underweight, and $29 \%$ had average weight; the remaining were overweight and obese.

Table 2 shows that 185/380 (48.7\%) mentioned having other chronic diseases; only 6/185 (3.2\%) did not use drugs for this disease. Hypertension was the most frequent chronic disease that accompanies diabetes in about 153 patients (64\%). Note that patients may have more than one other chronic condition in addition to DM.

Near one-third of the sample (30.8\%) was diagnosed with DM before more than ten years. Although 244 of the patients (64.2\%) were regularly measuring their glucose level, $60.8 \%$ of patients never visit their physicians regularly because $46.3 \%$ feel no need to that, and $34.2 \%$ had an economic barrier. The treatment prescribed by doctors was 
Table 1. Socio-demographic features of the 380 diabetic patients who participated in the study

\begin{tabular}{|c|c|c|c|}
\hline & Variables & Frequency & Percent \\
\hline \multirow{2}{*}{ Gender } & Male & 171 & 45.0 \\
\hline & Female & 209 & 55.0 \\
\hline \multirow{3}{*}{ Marital status } & Single & 80 & 21.0 \\
\hline & Married & 253 & 66.6 \\
\hline & Divorced or widowed & 47 & 12.4 \\
\hline Place of living & Urban & 349 & 91.8 \\
\hline \multirow{4}{*}{ Educational status } & No education/ read and write & 47 & 12.4 \\
\hline & Primary and intermediate & 61 & 16.0 \\
\hline & Secondary school & 89 & 23.4 \\
\hline & College and above & 183 & 43.2 \\
\hline \multirow{3}{*}{ Occupation } & Governmental employee & 97 & 25.5 \\
\hline & Retired & 77 & 20.3 \\
\hline & Not employed or student & 149 & 39.2 \\
\hline \multirow{3}{*}{ Average family's monthly salary } & Less than 500,000 IQ. D* & 121 & 31.8 \\
\hline & Between 500000-1million IQ. D* & 133 & 35.0 \\
\hline & More than one million IQ. $\mathrm{D}^{*}$ & 126 & 33.2 \\
\hline \multirow{4}{*}{$\begin{array}{l}\text { Weight according to Body Mass } \\
\text { Index (BMI) }\end{array}$} & Underweight & 10 & 2.6 \\
\hline & Normal weight & 110 & 29.0 \\
\hline & Overweight & 152 & 40.0 \\
\hline & Obese & 108 & 28.4 \\
\hline
\end{tabular}

*Iraqi Dinars

Table 2. The presence of other chronic conditions co-existing with DM

\begin{tabular}{|c|c|c|c|}
\hline & Variables & Frequency & Per cent \\
\hline \multirow{2}{*}{ Presence of other chronic diseases } & Yes & 185 & 48.7 \\
\hline & No & 195 & 51.3 \\
\hline \multirow{2}{*}{$\begin{array}{l}\text { Take drugs for other chronic } \\
\text { diseases (185) }\end{array}$} & Yes & 179 & $96.8 \%$ \\
\hline & No & 6 & $3.2 \%$ \\
\hline \multirow{3}{*}{ Type of other chronic diseases } & Hypertension & 153 & $64 \%$ \\
\hline & Heart disease & 55 & $23 \%$ \\
\hline & Others & 19 & $8 \%$ \\
\hline
\end{tabular}

Table 3. Frequency distribution of variables related to diabetes mellitus disease among 380 patients

\begin{tabular}{|c|c|c|c|}
\hline & Variables & Frequency & Per cent \\
\hline \multirow{4}{*}{ Duration of $\mathrm{DM}^{*}$} & Less than a one year & 56 & 14.7 \\
\hline & $1-5$ years & 113 & 29.7 \\
\hline & $5-10$ years & 94 & 24.7 \\
\hline & More than ten years & 117 & 30.8 \\
\hline \multirow{3}{*}{$\begin{array}{l}\text { Management prescribed by doctors } \\
\text { for } \mathrm{DM}^{*}\end{array}$} & Oral tablets & 299 & $47.9 \%$ \\
\hline & Nutritional therapy & 182 & $29.2 \%$ \\
\hline & Insulin injection & 75 & $12.0 \%$ \\
\hline \multirow{2}{*}{$\begin{array}{c}\text { Do you measure your blood glucose } \\
\text { regularly? }\end{array}$} & Yes & 244 & 64.2 \\
\hline & No & 136 & 35.8 \\
\hline \multirow{2}{*}{ Do you visit your doctor regularly? } & Yes & 149 & 39.2 \\
\hline & No & 231 & 60.8 \\
\hline \multirow{4}{*}{$\begin{array}{l}\text { The Causes of not visiting doctors } \\
\text { regularly among } 231 \text { patients. }\end{array}$} & Economic causes & 79 & $34.2 \%$ \\
\hline & Feel no need, not important & 107 & $46.3 \%$ \\
\hline & Forget & 36 & $15.6 \%$ \\
\hline & Other causes like do not like doctors, coronavirus. & 9 & $3.9 \%$ \\
\hline
\end{tabular}

*Diabetes Mellitus

mainly oral tablets (47.9\%), nutritional therapy (29.2\%), insulin (12\%), and exercise (10.9\%) (Table 3).

Reasons for non-compliance to treatment were presented in Table 4. Among those $82 / 380$ (21.6\%) patients who did not adhere to their drugs, 32 patients (25.4\%) defined expensive drugs as a significant cause, followed by $19.8 \%$ who forget drugs, and $15.9 \%$ were careless about their treatment therapy. Only three patients (2.4\%) did not understand the correct way of using it. Near one quarter, $24 \%$ said they did not 
Table 4. Frequency of compliance to treatment and causes for non-compliance among type $2 \mathrm{DM}$ patients

\begin{tabular}{|c|c|c|c|}
\hline & Variables & Frequency & Per cent \\
\hline \multirow{2}{*}{$\begin{array}{l}\text { Do you compline with drug } \\
\text { therapy? }\end{array}$} & Yes & 298 & 78.4 \\
\hline & No & 82 & 21.6 \\
\hline \multirow{8}{*}{$\begin{array}{l}\text { Causes of non-compliance to oral } \\
\text { tablets }\end{array}$} & Feel no need for drugs & 5 & $4.0 \%$ \\
\hline & Careless & 20 & $15.9 \%$ \\
\hline & Lots of treatments & 12 & $9.5 \%$ \\
\hline & The side effect of drugs & 10 & $7.9 \%$ \\
\hline & Not understand the way & 3 & $2.4 \%$ \\
\hline & Forget & 25 & $19.8 \%$ \\
\hline & Long treatment period & 11 & $8.7 \%$ \\
\hline & Drugs not available & 8 & $6.3 \%$ \\
\hline \multirow{2}{*}{$\begin{array}{l}\text { Do you compline with food } \\
\text { prescribed by the doctor? }\end{array}$} & Yes, always & 78 & 20.5 \\
\hline & Yes, sometimes & 211 & 55.5 \\
\hline \multirow{5}{*}{$\begin{array}{c}\text { Causes of non-compliance to } \\
\text { healthy food }\end{array}$} & Not able to provide healthy food & 25 & $12.7 \%$ \\
\hline & Don't care & 123 & $62.4 \%$ \\
\hline & No time for prepare food & 22 & $11.2 \%$ \\
\hline & No one help in preparing the food & 21 & $10.7 \%$ \\
\hline & Not able to control my appetite & 6 & $3.0 \%$ \\
\hline \multirow{3}{*}{ Do you practice exercise? } & Yes, regularly & 37 & 9.7 \\
\hline & Yes, irregularly & 122 & 32.1 \\
\hline & No exercise at all & 221 & 58.2 \\
\hline \multirow{4}{*}{$\begin{array}{c}\text { causes of non-compliance to } \\
\text { exercise }\end{array}$} & No time & 93 & $32.9 \%$ \\
\hline & No suitable place & 67 & $23.7 \%$ \\
\hline & Not interested or care & 4 & $1.4 \%$ \\
\hline & Not able to do & 119 & $42.0 \%$ \\
\hline
\end{tabular}

adhere to the prescribed healthy dietary regime; the leading cause was carelessness in $62.4 \%$, followed by the inability to provide this type of food in $12.7 \%$. Only $39(9.7 \%)$ of patients practice regular exercise. Of the remaining 341patients, there were 221 who never do any exercise at any time, and the major causes were that they were not able to do it (42\%) and having no time (32.9\%).

The results of Table 5 found a significant association between occupation with the three types of treatment (drugs, diet, and exercise) with p-values $0.006,0.017$, and 0.020 in the same order.

The gender of the patients was associated with only exercise (pvalue $=0.008)$. Educational level was associated with compliance to diet and exercise ( $\mathrm{p}$-value $=0.021,0.002)$ in respectively. Age and marital status were significantly associated with drug and exercise adherence (p-value $<0.001$ ). The average family monthly salary was associated with only drug compliance ( $\mathrm{p}$-value $<0.001$ ), while the BMI category was associated with both diet and exercise ( $\mathrm{p}$-value for diet $=0.003$ and exercise $=0.023$ ).

\section{DISCUSSION}

As the adherence to treatment in patients living with chronic diseases like DM is of significant effect in controlling symptoms and preventing future complications, a community-based cross-sectional study was done to estimate the prevalence of treatment noncompliance among patients with type $2 \mathrm{DM}$ and also to determine the factors associated. The management of diabetes mellitus includes both pharmacologic and nonpharmacologic methods. To be well controlled and treated, patients need to comply with all doctor instructions to get the required objective from both approaches. Despite this reality, many patients never adhere to their suggested treatments and doctor advice which may be related to a lot of contributed factors [18].

In the current study, we noticed that the number of females who participate in the study slightly exceeds the number of males, and this may be related to the fact that females are generally more than males in our country [19] or were more interested in participation rather than males. Even there was no definite difference between both sexes in the prevalence of DM, previous studies found a significant increase in the prevalence of DM among women relative to men, and this also can explain the higher percentage of females in our sample $[20,21]$. The majority of the patients were overweight and obese because it is a known risk factor for type $2 \mathrm{DM}$. It was proven that obesity could cause a disturbance in the mechanism of insulin resistance in responsive cells, including liver, muscle, and adipocyte leading to reducing their responsiveness to insulin and, finally, type 2 DM [22-24]. Patients in this study mainly came from urban regions rather than rural areas, maybe because of ease of access to private clinics in city centres. In addition, people with higher educational levels tend to participate more than people with lower educational levels.

Literature assumed that patients with long-term conditions show a relatively low level of medication adherence, especially after six months from starting the treatment, and this is still the top priority for governmental and non-governmental organizations to work on $[12,25]$. However, the current study showed that more than threequarters of patients reported good compliance to medication and (21.6\%) missed their medication treatments. This result was better than rates showed the Indian diabetic population in 2018 with $29.7 \%$ noncompliance to medications [26]. Another study conducted in Ajman appeared an $84 \%$ compliance rate to treatment, and patients related this to expanded mindfulness and advantage from the broadly dispersed data 
Table 5. Association between compliance to treatment with the selected socio-demographic feature of patients.

\begin{tabular}{|c|c|c|c|c|c|c|c|c|c|c|c|c|c|}
\hline & \multirow[b]{2}{*}{ Variables } & & \multicolumn{2}{|c|}{$\begin{array}{c}\text { Compliance with } \\
\text { drug } \\
\end{array}$} & \multirow[b]{2}{*}{ P-value } & \multicolumn{3}{|c|}{$\begin{array}{c}\text { Compliance with healthy } \\
\text { diet }\end{array}$} & \multirow[b]{2}{*}{ p-value } & \multicolumn{3}{|c|}{$\begin{array}{c}\text { Compliance with the } \\
\text { exercise }\end{array}$} & \multirow[b]{2}{*}{ p-value } \\
\hline & & & $\stackrel{\Xi}{\varnothing}$ & $\stackrel{\circ}{z}$ & & $\sum_{\frac{\pi}{2}}^{\infty}$ & $\begin{array}{l}\mathscr{\Xi} \\
\text { हूँ } \\
\stackrel{\Xi}{0}\end{array}$ & 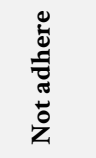 & & 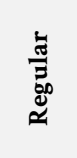 & 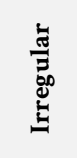 & 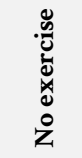 & \\
\hline \multirow{3}{*}{ Gender } & Male & No. & 139 & 32 & \multirow{3}{*}{0.219} & 37 & 96 & 38 & \multirow{3}{*}{0.743} & 22 & 64 & 85 & \multirow{3}{*}{0.008} \\
\hline & \multirow{2}{*}{ Female } & No. & 159 & 50 & & 41 & 115 & 53 & & 15 & 58 & 136 & \\
\hline & & $\%$ & 53.4 & 61 & & 52.6 & 54.5 & 58.2 & & 40.5 & 47.5 & 61.5 & \\
\hline \multirow{7}{*}{ Occupation } & \multirow{2}{*}{ Governmental } & No. & 75 & 22 & \multirow{7}{*}{0.006} & 22 & 54 & 21 & \multirow{7}{*}{0.017} & 8 & 43 & 46 & \multirow{7}{*}{0.020} \\
\hline & & $\%$ & 25.2 & 26.8 & & 28.2 & 25.6 & 23.1 & & 21.6 & 35.2 & 20.8 & \\
\hline & & No. & 70 & 7 & & 18 & 43 & 16 & & 6 & 16 & 55 & \\
\hline & Ketired & $\%$ & 23.5 & 8.5 & & 23.1 & 20.4 & 17.6 & & 16.2 & 13.1 & 24.9 & \\
\hline & self-employed & $\%$ & 15.8 & 12.2 & & 10.3 & 11.4 & 27.5 & & 10.8 & 13.1 & 16.7 & \\
\hline & & No. & 106 & 43 & & 30 & 90 & 29 & & 19 & 47 & 83 & \\
\hline & Not employed & $\%$ & 35.6 & 52.4 & & 38.5 & 42.7 & 31.9 & & 51.4 & 38.5 & 37.6 & \\
\hline & & No. & 278 & 71 & & 71 & 197 & 81 & & 35 & 110 & 204 & \\
\hline & Urban & $\%$ & 93.3 & 86.6 & & 91.0 & 93.4 & 89.0 & & 94.6 & 90.2 & 92.3 & \\
\hline Place of living & & No. & 20 & 11 & 0.50 & 7 & 14 & 10 & 0.428 & 2 & 12 & 17 & 0.639 \\
\hline & Kural & $\%$ & 6.7 & 13.4 & & 9 & 6.6 & 11.0 & & 5.4 & 9.8 & 7.7 & \\
\hline & & No. & 39 & 8 & & 9 & 19 & 19 & & 2 & 9 & 36 & \\
\hline & No education & $\%$ & 13.1 & 9.8 & & 11.5 & 9 & 20.9 & & 5.4 & 7.4 & 16.3 & \\
\hline & Below & No. & 44 & 17 & & 14 & 28 & 19 & & 5 & 10 & 46 & \\
\hline Educational & secondary & $\%$ & 14.8 & 20.7 & & 17.9 & 13.3 & 20.9 & 0.021 & 13.5 & 8.2 & 20.8 & 0.002 \\
\hline levels & & No. & 67 & 22 & 0.366 & 15 & 53 & 21 & 0.021 & 9 & 34 & 46 & 0.002 \\
\hline & secondary & $\%$ & 22.5 & 26.8 & & 19.2 & 25.1 & 23.1 & & 24.3 & 27.9 & 20.8 & \\
\hline & College \& above & No. & 148 & 35 & & 40 & 111 & 32 & & 21 & 69 & 93 & \\
\hline & Single & No. & 43 & 37 & & 19 & 47 & 14 & & 15 & 43 & 22 & \\
\hline & single & $\%$ & 14.4 & 45.1 & & 24.4 & 22.3 & 15.4 & & 40.5 & 35.2 & 10 & \\
\hline Marital status & Married & No. & 212 & 41 & $<0.001$ & 48 & 142 & 63 & 0426 & 19 & 74 & 160 & $<0.001$ \\
\hline Trratical status & ivranted & $\%$ & 71.1 & 50 & & 61.5 & 67.3 & 69.2 & 0.420 & 51.4 & 60.7 & 72.4 & \\
\hline & Divorced or & No. & 43 & 4 & & 11 & 22 & 14 & & 3 & 5 & 39 & \\
\hline & widow & $\%$ & 14.4 & 4.9 & & 14.1 & 10.4 & 15.4 & & 8.1 & 4.1 & 17.6 & \\
\hline & $<500000$ & No. & 81 & 40 & & 24 & 66 & 31 & & 15 & 34 & 72 & \\
\hline & IQ. D & $\%$ & $27.2 \%$ & 48.8 & & 30.8 & 31.3 & 34.1 & & 40.5 & 27.9 & 32.6 & \\
\hline Average & $500000-1$ & No. & 107 & 26 & $<0.001$ & 26 & 72 & 35 & 0771 & 6 & 44 & 83 & 0096 \\
\hline monthly salary & million & $\%$ & 35.9 & 31.7 & & 33.3 & 34.1 & 38.5 & 0.771 & 16.2 & 36.1 & 37.6 & 0.096 \\
\hline & More than 1 & No. & 110 & 16 & & 28 & 73 & 25 & & 16 & 44 & 66 & \\
\hline & million & $\%$ & 36.9 & 19.5 & & 35.9 & 34.6 & 27.5 & & 43.2 & 36.1 & 29.9 & \\
\hline & Under weight & No. & 5 & 5 & & 2 & 5 & 3 & & 0 & 3 & 7 & \\
\hline & under weignt & $\%$ & 1.7 & 6.1 & & 2.6 & 2.4 & 3.3 & & 0 & 2.5 & 3.2 & \\
\hline & & No. & 86 & 24 & & 22 & 69 & 19 & & 17 & 42 & 51 & \\
\hline & Normal weight & $\%$ & 28.9 & 29.3 & 0172 & 28.2 & 32.7 & 20.9 & 0.003 & 45.9 & 34.4 & 23.1 & 0.023 \\
\hline Bo & Overweight & No. & 121 & 31 & 0.172 & 36 & 89 & 27 & 0.003 & 15 & 48 & 89 & 0.020 \\
\hline & Overweignt & $\%$ & 40.6 & 37.8 & & 46.2 & 42.2 & 29.7 & & 40.5 & 39.3 & 40.3 & \\
\hline & & No. & 86 & 22 & & 18 & 48 & 42 & & 5 & 29 & 74 & \\
\hline & Ubese & $\%$ & 28.9 & 26.8 & & 23.1 & 22.7 & 46.2 & & 13.5 & 23.8 & 33.5 & \\
\hline & Mean ag & & 51.47 & 40.51 & $<0.001$ & 49.86 & 47.49 & 52.21 & 0.073 (one & 42.76 & 43.05 & 53.51 & $<0.001$ \\
\hline Age in years & Standard devi & tion & 16.10 & 16.47 & $\begin{array}{l}\text { (Independent } \\
\mathrm{t} \text { - test) }\end{array}$ & 18.39 & 16.96 & 14.45 & $\begin{array}{c}\text { way } \\
\text { ANOVA) }\end{array}$ & 19.44 & 17.75 & 14.26 & $\begin{array}{l}\text { (one way } \\
\text { ANOVA) }\end{array}$ \\
\hline
\end{tabular}

concerning their disease and medications straightforwardly from their doctor and involve them in decision making about their treatment [27].

Patients within the current study appeared that they were more adherence to dietary instructions than practising physical activity. Our rate was nearly similar to the rate shown in Alexandra, Egypt, which found that $58.8 \%$ of patients complied with diet while only (51.7\%) were compliant to exercise [28]. This may be due to easy to control diet and follow doctor instructions than performing a regular healthy exercise the simpler to take after healthy diet instructions than an exercise administration. The highest percentage of the patients said they could not exercise; others mentioned having no time or suitable place to do 
so. In Northern Finland, dietary adherence has been mentioned by (62.4\%) diabetic patients [29].

The gender of the patient was significantly associated with the level of practising exercise. Females were less likely to be compliant with exercise than males, and this is not surprising in our community, which restricts females' freedom and their jobs in homes, making them busy most of the time-increasing educational level significantly leading to increasing compliance to medications, healthy diet, and exercise. This has already been proved by studies conducted in Saudi Arabia and the United Arab Emirates (UAE) [30,31] and may be related to their awareness of diabetic complications, which may be leading to ending their lives [32]. Furthermore, the married patients showed a significantly higher percentage of drug and exercise which can be linked to the tremendous support their spouse or other relations. Similar results were also shown in the Saudi Arabia study [30].

In this study, the occupation is associated with treatment adherence, like in the Bisha governorate of Saudi Arabia [33]. Nonemployed or student patients who had a higher percentage of compliance in all aspects of treatment (drug therapy, diet, and exercise) may be due to the availability of time to take care of their health and follow doctor's instructions. The monthly family salary is significantly associated with compliance to drug therapy as a close-quarter of patients mentioned the expensive cost of the drugs as a barrier to adhere to medication. Similarly, Wabe et al. concluded that $37 \%$ of nonadherent Ethiopian patients had financial limitations [34]. This is a significant problem because numerous anti-diabetic medications are so expensive that patients need to use them continuously. This problem should be resolved by arranging free drugs for patients from the hospitals [35]. Patients with lower monthly salaries were less likely to adhere to their medications than those with a monthly salary between (500.000 -1 million IQ. D) or greater than 1 million (note that each $1 \$$ averaged 1450-1500 Iraqi Dinars). Previous studies conducted in different world regions reported lower income led to lower medication adherence $[18,34,36,37]$. They explained this as those who obtain more money are paying more for their health and treatment, and they can pay for varied suppliers of medication information, including books, television, radios, and magazines. Forgetfulness was the second most common reason for non-compliance to drugs in our current study. On the contrary, our finding was shown to be the most typical reason for non-compliance by Nigerian patients [38]. Most of the participants in this study were in their seventh to the eighth decade and may complain of memory impairment problems.

According to Barclay et al. [39], dietary modification is required for type 2 diabetes mellitus patients. This includes a diet low in saturated fat, sodium and carbohydrate, and high fibre contents. The importance of dietary modification in patients with type 2 diabetes is to decrease body weight by about 5-10\%, controlling blood sugar, and prevent or reduce future complications like cardiovascular and renal problems. Unfortunately, most patients in this study suffer from overweight and obesity, which was found to be associated with their compliance to dietary instructions and exercise.

\section{LIMITATIONS}

There are some limitations in our study, such as the majority of respondents were with high educational levels, and the selected clinics were from city centres only. The other problem we faced was the
Coronavirus pandemic which affected the number of samples, and perhaps there are some non-committal people that we could not see to know the reasons for their non-compliance.

\section{CONCLUSION AND RECOMMENDATIONS}

In conclusion, it turns out that the majority of the patients respond to the drugs prescribed by their doctor. In comparison, a minority do not get them due to the expense of the drugs. Finally, another line was studied, which is the food restriction. Here, a significant number of the collected sample do not comply with a healthy diet due to their carelessness. As for exercise, ups and downs ranged from no time to do sport to not being able to.

This study recommends a governmental intervention with the costs and accessibility of the drugs utilized to treat DM. Awareness programs encourage a healthy lifestyle. Furthermore, define its significance for individuals with type $2 \mathrm{DM}$. Further studies are recommended to assess different adherence and non-adherence issues within the region.

Author contributions: All authors were involved in concept, design, collection of data, interpretation, writing, and critically revising the article. All authors approve final version of the article.

Funding: The authors received no financial support for the research and/or authorship of this article.

Declaration of interest: Authors declare no competing interest.

Data availability: Data generated or analysed during this study are available from the authors on request.

\section{REFERENCES}

1. Gulabani M, John M, Isaac R. Knowledge of diabetes, its treatment and complications amongst diabetic patients in a tertiary care hospital. Indian J Community Med. 2008; 33(3): 204-6. (doi: 10.4103/0970-0218.42068).

2. Vivian EM. Type 2 diabetes in children and adolescents--the next epidemic?. Curr Med Res Opin. 2006; 22(2): 297-306. (doi: 10.1185/030079906X80495).

3. Anjana RM, Ali MK, Pradeepa R, et al. The need for obtaining accurate nationwide estimates of diabetes prevalence in India rationale for a national study on diabetes. Indian J Med Res. 2011; 133(4): 369-380.

4. Oputa R N, and Chinenye S. Diabetes mellitus: a global epidemic with potential solutions. African Journal of Diabetes mellitus 2012; 20(2): 33-5.

5. Powers MA, Bardsley J, Cypress M, et al. Diabetes self-management education and support in type 2 diabetes: A joint position statement of the American Diabetes Association, the American Association of Diabetes Educators, and the Academy of Nutrition and Dietetics. Clin Diabetes. 2016; 34(2): 70-80. (doi: 10.2337/diaclin.34.2.70). 
6. Sharma T, Kalra J, Dhasmana DC, Basera H. Poor adherence to treatment: A major challenge in diabetes. JIACM 2014; 15(1): 26-9.

7. Hernández-Ronquillo L, Téllez-Zenteno JF, Garduño-Espinosa J, González-Acevez E. Factors associated with therapy noncompliance in type-2 diabetes patients. Salud Publica Mex. 2003; 45(3): 191-7. (doi: 10.1590/s0036-36342003000300008).

8. American Diabetes Association. Diagnosis and classification of diabetes mellitus [published correction appears in Diabetes Care. 2010 Apr; 33(4): e57]. Diabetes Care. 2010; 33 Suppl 1(Suppl 1): S62-S69. (doi: 10.2337/dc10-S062).

9. Sherwani SI, Khan HA, Ekhzaimy A, Masood A, Sakharkar MK. Significance of HbA1c Test in Diagnosis and Prognosis of Diabetic Patients. Biomark Insights. 2016; 11: 95-104. (doi: 10.4137/BMI.S38440).

10. Rwegerera GM. Adherence to anti-diabetic drugs among patients with Type 2 diabetes mellitus at Muhimbili National Hospital, Dar es Salaam, Tanzania- A cross-sectional study. Pan Afr Med J. 2014; 17: 252. (doi: 10.11604/pamj.2014.17.252.2972).

11. Cramer JA. A systematic review of adherence with medications for diabetes. Diabetes Care 2004; 27(5): 1218-24. (doi: 10.2337/diacare.27.5.1218).

12. Osterberg L, Blaschke T. Drug therapy Adherence to medication. N Eng J Med 2005; 353: 487-97. (doi: 10.1056/NEJMra050100).

13. Joan N, Erisa O, Agatha P. Non-adherence to diabetes treatment at Mulago Hospital in Uganda: Prevalence \& associated factors. African Health Sciences 2008; 8(2): 67-73.

14. Turpin RS, Blumberg PB, Sharda CE, Salvucci LAC, Haggert B, Simmons JB. Patient adherence: Present state and future directions. Population Health Management 2007; 10(6): 305-10.

15. Almaghaslah D, Abdelrhman A K, AL-Masdaf S K, et al. Factors contributing to non-adherence to insulin therapy among type 1 and type 2 diabetes mellitus patients in Asser region, Saudi Arabia. Biomedical Research 2018; 29(10): 2090-5. (doi: 10.4066/biomedicalresearch.29-18-503).

16. Al-Khfajy W S, Aboddy A A, Arif I S. Diabetic Patients' Adherence to Medications and Related Factors in A Sample of The Iraqi Population. Proceedings of 177 th The IIER International Conference, Istanbul, Turkey, 20th -21st July 2018: 51-55.

17. Center for Disease Control and Prevention (CDC). Healthy Weight, Nutrition, and Physical Activity. About Adult BMI (2020). Available at: https://www.cdc.gov/healthyweight/assessing/bmi/ adult_bmi/index.html
18. Gelaw BK, Mohammed A, Tegegne GT, et al. Nonadherence and contributing factors among ambulatory patients with antidiabetic medications in Adama Referral Hospital. J Diabetes Res. 2014; 2014: 617041. (doi: 10.1155/2014/617041).

19. The World Bank. Population, female-Iraq [\% of total population] (2020). Available at: https://data.worldbank.org/indicator/ SP.POP.TOTL.FE.ZS?locations=IQ

20. Talukder A, Hossain MZ. Prevalence of diabetes mellitus and its associated factors in Bangladesh: Application of two-level logistic regression model. Sci Rep 2020; 10: 10237. (doi: 10.1038/s41598020-66084-9).

21. Yang L, Shao J, Bian Y, Wu H, Shi L, Zeng L, Li W, Dong J. Prevalence of type 2 diabetes mellitus among inland residents in China (2000-2014): A meta-analysis. J Diabetes Investig. 2016 Nov; 7(6): 845-52. (doi: 10.1111/jdi.12514).

22. Abdullah A, Peeters A, de Courten M, Stoelwinder J. The Magnitude of Association between Overweight and Obesity and The Risk of Diabetes: A Meta-Analysis of Prospective Cohort Studies. Diabetes Res Clin Pract. 2010 Sep; 89(3): 309-19. (doi: 10.1016/j.diabres.2010.04.012).

23. Wang S, Ma W, Yuan Z, et al. Association Between Obesity Indices and Type 2 Diabetes Mellitus among Middle-Aged and Elderly People in Jinan, China: A Cross-Sectional Study. BMJ Open 2016; 6: e012742. (doi: 10.1136/BMJ open-2016-012742).

24. Siddiqui S. Obesity and Diabetes: Interrelationship. Adv Obes Weight Manag Control 2018; 8(2): 155-8. (doi: 10.15406/aowmc.2018.08.00233).

25. Vrijens B, De Geest S, Hughes DA, et al. A new taxonomy for describing and defining adherence to medications. $\mathrm{Br} \mathrm{J}$ Clin Pharmacol. 2012; 73(5): 691-705. (doi: 10.1111/j.1365-2125.2012. 04167.x).

26. Prithika UY, Paul CM, Nethaji VS, et al. A study on noncompliance to treatment in a Chennai based diabetic population. International Journal of Community Medicine and Public Health 2018; 5(12): 5465-8. (doi: 10.18203/2394-6040.ijcmph20184835).

27. Arifulla M, John LJ, Sreedharan J, Muttappallymyalil J, Basha SA Patients' adherence to anti-diabetic medications in a hospital at Ajman, UAE. Malays J Med Sci. 2014 Jan; 21(1): 44-9.

28. Ibrahim NK, Attia SG, Sallam SA, Fetohy EM, El-Sewi F Physicians' therapeutic practice and compliance of diabetic patients attending rural primary health care units in Alexandria. J Family Community Med 2010; 17(3): 121-8. (doi: 10.4103/13191683.74325) 
29. Toljamo M, Hentinen M. Adherence to self-care and glycaemic control among people with insulin-dependent diabetes mellitus. J Adv Nurs. 2001 Jun; 34(6): 780-6. (doi: 10.1046/j.13652648.2001.01808. x).

30. Ataur RK, Zaki N, Lateef AA, et al. Factors contributing to noncompliance among diabetics attending primary health center at $\mathrm{Al}$ Hasa District of Saudi Arabia. Journal of Family and Community Medicine 2012; 19(1): 23-32. (doi: 10.4103/2230-8229.94008).

31. Currie CJ, Peyrot M, Morgan CL, et al. The impact of treatment noncompliance on mortality in people with type 2 diabetes. Diabetes Care 2012 Jun; 35(6): 1279-84. (doi: 10.2337/dc11-1277).

32. Al-Rasheedi AA. The role of educational level in glycemic control among patients with type II diabetes mellitus. Int J Health Sci (Qassim). 2014; 8(2): 177-87. (doi: 10.12816/0006084).

33. Alqarni AM, Alrahbeni T, Qarni AA, Qarni HMA. Adherence to diabetes medication among diabetic patients in the Bisha governorate of Saudi Arabia - a cross-sectional survey. Patient Prefer Adherence. 2018; 13: 63-71. (doi: 10.2147/PPA.S176355).

34. Wabe NT, Angamo MT, Hussein S. Medication adherence in diabetes mellitus and self-management practices among type-2 diabetics in Ethiopia. N Am J Med Sci 2011; 3(9): 418-23. (doi: 10.4297/najms.2011.3418).
35. Zhou X, Shrestha SS, Shao H, Zhang P. Factors contributing to the rising national cost of glucose-lowering medicines for diabetes during 2005-2007 and 2015-2017. Diabetes Care Oct 2020; 43(10): 2396-402. (doi: 10.2337/dc19-2273).

36. Kassahun A, Gashe F, Mulisa E, Rike WA. Non-adherence and factors affecting adherence of diabetic patients to anti-diabetic medication in Assela General Hospital, Oromia Region, Ethiopia. J Pharm Bioallied Sci. 2016; 8(2): 124-9. (doi: 10.4103/09757406.171696).

37. Yusuff KB, Obe O, Joseph BY. Adherence to anti-diabetic drug therapy and self-management practices among type- 2 diabetics in Nigeria. Pharm World Sci. 2008; 30(6): 876-83. (doi: 10.1007/s11096-008-9243-2).

38. Abdulazeez F I, Omole M, Ojulari SL. Medication Adherence amongst Diabetic Patients in a Tertiary Healthcare Institution in Central Nigeria. Tropical Journal of Pharmaceutical Research June 2014; 13(6): 997-1001. (doi: 10.4314/tjpr.v13i6.25).

39. Barclay A, Gilbertson H, Marsh K, Smarth C. Dietary Management in diabetes. Australian family physician. 2010; 39(8): 579-83. 